\title{
Correction to: Gender Wage Inequality and Economic Recession
}

\section{Somasree Poddar ${ }^{1}$}

Published online: 7 November 2017

(C) The Indian Econometric Society 2017

\section{Correction to: J. Quant. Econ. DOI 10.1007/s40953-016-0070-3}

In the originally published article the author's family name was misspelt as "Podder" instead of "Poddar".

The original article can be found online at https://doi.org/10.1007/s40953-016-0070-3.

$\bowtie$ Somasree Poddar

roychowdhurysomasree10@gmail.com

1 Department of Economics, Lady Brabourne College, Flat No 5A, 360 Dum Dum Park, Kolkata 700055, India 